\title{
Eventos focalizadores e a pandemia da COVID-19: a renda básica emergencial na agenda governamental brasileira
}

\author{
Felipe Gonçalves Brasil 1 \\ Ana Cláudia Niedhardt Capella ${ }^{2}$ \\ Leandro Teodoro Ferreira ${ }^{3}$ \\ 1 Universidade de São Paulo / Escola de Artes, Ciências e Humanidades, São Paulo / SP - Brasil \\ 2 Universidade Estadual Paulista "Júlio de Mesquita Filho" / Faculdade de Ciências e Letras, Araraquara / SP - Brasil \\ ${ }^{3}$ Universidade Federal do ABC, São Paulo / SP - Brasil
}

\begin{abstract}
Observar e analisar as causas, os efeitos e as múltiplas consequências econômicas, sociais e sanitárias da pandemia da COVID-19 têm sido primordiais não apenas para a compreensão desse fenômeno mundial, mas também para a elaboração de alternativas e soluções que minimizem os impactos na vida das populações ao redor do mundo. Este artigo tem como principal objetivo entender a ascensão da renda básica emergencial como alternativa viável de política pública no cenário brasileiro, por meio do Auxílio Emergencial. Baseado na literatura de agenda-setting, em específico no conceito de eventos focalizadores (focusing events), recuperamos um breve histórico das políticas de transferência de renda e de combate à pobreza e os principais atores envolvidos, para entender mudanças, adaptações e soluções propostas para que a alternativa de renda básica emergencial pudesse ser considerada e aceita neste momento específico de crise.
\end{abstract}

Palavras-chave: COVID-19; eventos focalizadores; agenda-setting; renda básica; auxílio emergencial.

\section{Eventos focales y la pandemia de COVID-19: La renta básica de emergencia en la agenda del gobierno brasileño}

Observar y analizar las causas, efectos y las múltiples consecuencias económicas, sociales y de salud de la pandemia de COVID-19 han sido primordiales no solo para comprender este fenómeno mundial, sino también para el desarrollo de alternativas y soluciones que minimicen los impactos en la vida de poblaciones de todo el mundo. El principal objetivo de este artículo es entender el reconocimiento de la renta básica de emergencia como una alternativa viable de política pública en el escenario brasileño, que ha adoptado un "beneficio de emergencia". Con base en la literatura de agenda-setting, específicamente en el concepto de eventos focales, recuperamos una reseña de las políticas de transferencia de renta, de reducción de la pobreza y los principales actores involucrados, para comprender los cambios, adaptaciones y soluciones propuestas para que la alternativa de renta básica de emergencia pudiera considerarse y aceptarse en este momento específico de crisis.

Palabras clave: COVID-19; eventos focales; agenda-setting; renta básica; beneficio de emergencia.

\section{Focusing events and the COVID-19 pandemic: the emergency basic income on the Brazilian agenda}

Observing and analyzing the causes, effects, and multiple economic, social, and health consequences of the COVID-19 pandemic have been essential to understand this worldwide phenomenon and find solutions that minimize the impacts on peoples' lives. This article aims to understand the rise of the emergency basic income as a viable policy to tackle the pandemic in Brazil. Based on the agenda-setting literature, specifically on the concept of focusing events, we present a brief history of cash transfer and poverty reduction policies, as well as the actors involved. The study discusses the changes, adaptations, and solutions proposed during the formulation of the emergency basic income as a policy to be considered and effectively adopted in this specific moment of crisis.

Keywords: COVID-19; focusing events; agenda-setting; basic income; emergency benefit. 


\section{AGRADECIMENTOS}

Agradecemos aos financiamentos institucionais da FAPESP, processos 2018/16289-3; 2020/07485-3 e 2021/02716-0; e do CNPq, processo 424398/2018-4 - chamada MCTIC/CNPq No 28/2018, que permitiram a realização das pesquisas que resultaram neste artigo.

\section{INTRODUÇÃO}

A renda básica como alternativa a problemas públicos não é novidade no Brasil. Do Projeto de Lei do Senado ${ }^{\circ}$ 80, de 1991, proposto pelo então senador Eduardo Suplicy (PT-SP), até os desdobramentos e os redesenhos dessa proposta na formulação de outras políticas sociais, como o Programa Bolsa Família, em 2003, a transferência de renda ganhou destaque nos estudos de políticas sociais e na formulação de políticas públicas no Brasil (Bichir, 2010; Coêlho, 2013; Silva, Yazbek \& Giovanni, 2012; Sposati, 1997).

A transferência de renda não condicionada, no entanto, cujo debate se estende por quase 3 décadas no cenário nacional, entre idas e vindas na lata de lixo (March, Olsen \& Cohen, 1972), ${ }^{1}$ parece ter encontrado na pandemia da COVID-19 um gatilho que a coloca em destaque no processo de agendamento e de formulação de políticas públicas (Brasil, 2020; Brasil \& Capella, 2020). Eventos como a pandemia da COVID-19 podem ser compreendidos pela literatura de políticas públicas como exemplos de "eventos focalizadores" (focusing events) (Birkland, 1997, 1998; Kingdon, 2003) que têm potencial para concentrar a atenção de diversos atores para uma questão específica e conectar alternativas já existentes a novas construções de problemas públicos.

Este artigo tem como principal objetivo analisar de que forma a renda básica, presente no debate brasileiro desde o início dos anos 1990, ascende à agenda governamental e se torna uma alternativa viável para formulação de políticas públicas que respondem aos efeitos da pandemia da COVID-19 no Brasil. Para isso, esta pesquisa exploratória utiliza métodos qualitativos como a revisão da literatura e o rastreamento de processo (process tracing). A revisão bibliográfica envolve tanto a revisão e a interpretação de extensa produção sobre as políticas de transferência de renda, mapeando e definindo o objeto de análise, quanto os preceitos teóricos da formação de agenda e o papel dos eventos focalizadores em processos de mudança em políticas públicas.

Para a construção de evidências empíricas que expliquem o processo que correlaciona a origem - ponto A, evento focalizador: pandemia da COVID-19 - com a consequência - ponto B, renda básica emergencial -, são utilizadas fontes de informações e evidências extraídas de reportagens jornalísticas, artigos de opinião, documentos legais advindos do governo, do Ministério da Saúde e de organismos internacionais como a Organização Mundial da Saúde (OMS), além de entrevistas e produção de atores de movimentos sociais envolvidos no processo. A variedade de fontes é prerrogativa importante para a obtenção de evidências empíricas necessárias à compreensão e à análise dos fatos apresentados de forma correlacional e causal entre o evento focalizador e a aprovação da renda básica emergencial no Brasil.

\footnotetext{
${ }^{1}$ Processos decisórios que ocorrem em situações de ambiguidade, abrangendo múltiplos atores com preferências inconsistentes, são denominados de "processos de lata do lixo" (March, 2009). Eles foram analisados originalmente por March et al. (1972), que cunharam o termo "modelo da lata do lixo" - no original, garbage can model - para designar oportunidades de escolha envolvendo indivíduos, problemas e soluções, elementos que se conectam de forma diferente ao longo do tempo. O processo decisório em organizações governamentais assume muitas vezes tais características: as chamadas "anarquias organizadas" (March et al., 1972).
} 
Além desta Introdução, o artigo é estruturado em 4 partes. Na primeira, resgatamos o debate acerca do conceito de Renda Básica no Brasil, destacando, de forma breve, sua inserção no debate político acadêmico brasileiro. A segunda, de caráter teórico, apresenta o conceito de eventos focalizadores inseridos na literatura de formação de agenda e de formulação de políticas públicas. O objetivo dessa seção é contextualizar e apresentar a forma como esses eventos têm grande potencial de provocar mudanças em políticas públicas. A terceira, de discussão e desenvolvimento, entrelaça os debates entre o objeto e a teoria, apresentando uma possibilidade de investigação sobre mudança de agenda e formulação de políticas públicas ao interpretar e analisar a pandemia da COVID-19 como evento focalizador que proporcionou a adoção da renda emergencial como uma das alternativas para solucionar ou amenizar os drásticos efeitos provocados pela doença no Brasil. Por fim, nas Considerações finais, além de apresentar as principais características dos eventos focalizadores aplicados ao caso da renda básica, o artigo oferece novas possibilidades e olhares teóricos para os estudos da formação de agenda e da formulação de políticas no Brasil sob contextos de crise, ainda pouco estudados pela literatura nacional.

\section{RENDA BÁSICA}

Os debates e as proposições sobre a renda mínima e o imposto de renda negativo permeiam o meio acadêmico brasileiro desde a década de 1970, sobretudo com as contribuições de Antonio Maria da Silveira (1975), Edmar Bacha e Mangabeira Unger (1978). No Brasil, as formas de garantia de renda transitam e permeiam os contornos da construção e da consolidação das políticas sociais brasileiras. Isso acontece porque é no período de redemocratização brasileira, nos primeiros anos da década de 1990, que, apesar da pressão de atores da sociedade civil e dos esforços de parte da classe política, a regulamentação da área da assistência social e as propostas nela inseridas, como a transferência de renda não condicionada, encontram dificuldades de consolidação e de avanços reais, marcadamente pela Lei Orgânica da Assistência Social e pela previsão nela contida do Benefício de Prestação Continuada, atendendo aos dispositivos constitucionais de 1988.

O período, marcado por forte fricção institucional, culminou, do ponto de vista político, no impeachment de Fernando Collor de Mello, mas teve, além da turbulência particular, movimentos de desconstrução institucional dos marcos alcançados com a Constituição de 1988, com declarada tentativa de revisão do capítulo da Ordem Social previsto na Carta Magna (Fagnani, 2017). As altas taxas de inflação, desemprego, miséria e debilidade econômica do país foram enfrentadas com o padrão de política social inaugurado pela Constituição, que, em verdade, levou a um longo, complexo e lento processo de descentralização federativa de ações voltadas ao combate à pobreza e à superação da desigualdade social, ainda que o desafio geral de alcançar esses objetivos tenha se mantido como responsabilidade de todos os entes da federação (Bichir, 2010; Silva et al., 2012).

É nesse cenário de consolidação das políticas sociais desenhadas em 1988 que os programas de garantia de renda passam a se desenvolver. $O$ debate sobre a renda mínima e a transferência de renda como alternativa para solução de problemas nacionais, por sua vez, ganharia contornos institucionais quando o então senador Eduardo Suplicy (PT-SP) apresenta o Projeto de Lei nº 80, em abril de 1991. Em função do debate público intenso em torno do tema, a proposta avançou rapidamente no Senado, onde foi aprovada em dezembro do mesmo ano, antes de seguir para a Câmara dos Deputados, onde nunca foi aprovada em definitivo. 
O debate acadêmico nos anos seguintes e a atuação de governos em todos os níveis federativos evidenciam, de forma muito clara, que a proposta da renda mínima formalizada por Suplicy marcou um ponto de inflexão importante sobre a transferência de renda como solução viável na seleção de alternativas a problemas públicos, apoiada, empiricamente, no efetivo desdobramento em políticas públicas adotadas por diversos níveis de governo (Bichir, 2010; Coêlho, 2013; Leite \& Peres, 2015; Silva et al., 2012; Sposati, 1997). Os anos que se seguiram atraíram atenção para a renda mínima em função da enorme quantidade de programas locais de transferências de renda. Marta Farah (2008), por exemplo, identifica que a difusão de políticas entre os entes federativos se caracterizava naquele momento, graças à natureza comum do problema da pobreza enfrentado por diversos municípios na década de 1990, como um estímulo para a adoção de soluções aos moldes de uma renda mínima.

As políticas de transferência de renda, no entanto, nascem de forma descentralizada e descoordenada, por fora da institucionalidade da assistência social, cujo sistema e burocracia ainda eram precários e pouco organizados no Brasil até a virada do século. Ainda que alguns avanços possam ser verificados ao longo do governo de Fernando Henrique Cardoso, como a regulamentação do Fundo Nacional de Assistência Social e a criação do Fundo de Combate e Erradicação da Pobreza, por meio da Emenda Constitucional no 31, de dezembro de 2000, por exemplo, o processo de mudança e de centralização da área de assistência social ocorre, então, a partir do governo de Luiz Inácio Lula da Silva (2003-2010), dando a essas políticas de transferência de renda maior visibilidade e articulação, sobretudo com a criação do Ministério do Desenvolvimento Social (MDS) e a estruturação do Sistema Único de Assistência Social (Suas), que passam a concentrar uma agenda de políticas sociais mais forte e voltada ao combate à pobreza e à desigualdade, proporcionando maior institucionalização e coordenação de ações e programas (Bichir, 2016).

O período que engloba os 2 mandatos de Lula é de extrema relevância para o debate da renda básica e as ações de transferência de renda, já que, ao mesmo tempo que essas alternativas se tornavam reais no debate político, a concentração de atores e ideias no MDS ajudava a consolidar uma comunidade de política pública, permeada por atores de comunidade epistêmica, por policymakers e atores da sociedade civil, ação fundamental para os processos de manutenção da agenda e de formulação de políticas em torno do problema da pobreza e do combate à desigualdade social. Tal comunidade de política pública se assenta justamente nas capacidades e na experiência adquiridas por seus participantes por meio do processos de aprendizagem ao longo dos sucessivos episódios que levaram à transferência da política de renda mínima como solução de política de combate à pobreza por todo o espectro do federalismo brasileiro, tanto em sentido horizontal quanto em sentido vertical (Leite \& Peres, 2015).

Esse processo se intensifica, do ponto de vista institucional, porque essa mesma comunidade é capaz de transferir elementos como experiência de coordenação e desenhos de política para conformar em nível federal o Programa Bolsa Família (PBF) com grande similaridade ao arranjo adotado no Programa de Garantia de Renda Mínima Familiar de São Paulo:

As estratégias de negociação e busca de adesão dos entes intramunicipais, órgãos e autarquias foram fundamentais para a implementação do programa de São Paulo, configurando um acúmulo de experiências de implementação em contexto político e institucional descentralizado, que se demonstrou particularmente importante na formulação e implementação do desenho institucional do Programa Bolsa Família (Leite \& Peres, 2015). 
Ao mesmo tempo, é intenso o debate sobre a crescente aproximação de organismos multilaterais, como o Banco Mundial, da agenda de superação da pobreza. Seu receituário passa a incluir, então, políticas de renda mínima na forma de Programas de Transferência de Renda Condicionada (PTRC) como alternativa para países que têm pela frente a necessidade de estruturar suas políticas de enfrentamento de questões sociais. Trata-se de programas que têm como características fundamentais a focalização no público mais pobre, a necessidade de contrapartidas por parte de beneficiários, geralmente na forma de condicionalidades relacionadas à saúde e à educação, bem como o pagamento em dinheiro de uma soma que garanta um mínimo de subsistência (Soares, 2010).

O debate passa a caminhar por 2 vias distintas: a da renda básica de caráter universal e as transferências de caráter condicionado. A associação entre as políticas de transferência de renda e a Renda Básica não era descabida, mas elas não podem ser confundidas. Ambas são políticas que têm como ação concreta o pagamento de valores monetários de forma periódica ao seu públicoalvo. A diferença primordial da Renda Básica para os conhecidos programas de transferências de renda, com destaque para o PBF, estava principalmente em sua proposta universal, desvinculada de condicionalidades e de contrapartidas. Tanto esse processo de difusão de políticas descrito até aqui quanto a construção de uma narrativa em torno da evolução das propostas de garantia de renda são narrados, do ponto de vista político, pelo próprio ex-senador Eduardo Suplicy (2013), que procura aproximar o alcance obtido pelas políticas de garantia de renda, ainda que de caráter condicionado, de sua proposta de renda básica de Cidadania, aprovada no Congresso Nacional no contexto das discussões do PBF (Ferreira, 2019). Bichir, por exemplo, aponta que a iniciativa de autoria de Suplicy, a Lei Federal ${ }^{\circ} 10.835$, de 2004, que determina a criação de uma renda básica de cidadania universal e incondicional,

sinalizou, logo no início do governo Lula, a intenção de transformar os programas de transferência de renda associados a condicionalidades em programas de garantia de uma renda básica de cidadania, incondicionais. No entanto, toda discussão posterior focou-se nos programas de transferência de renda condicionada (Bichir, 2010).

Parte da literatura que se dedica a estudar a escolha pelas transferências de rendas condicionadas em detrimento da renda básica, universal e incondicional nas políticas de combate à pobreza e à desigualdade social aponta para um processo que, ao longo de uma década do PBF, faria com que sua expansão gradual tivesse a renda básica como ponto de chegada. Em 2014, por exemplo, ao tratar da expressiva expansão do PBF, Josué Pereira da Silva levanta razões para considerar significativa a argumentação de que os avanços continuados do PBF, ainda que de forma incremental, levariam a um programa cujo escopo seria maior e, talvez, universal:

o crescente do número de beneficiários incorporados ao programa desde sua criação em 2003 certamente contribui para que haja otimismo quanto a sua possível universalização, justificando em parte a tese de que ele caminharia em direção à instituição da renda básica de cidadania (Silva, 2014). 
O que se pode afirmar é que a renda básica universal nunca chegou a ser implementada, mesmo que tivesse sido considerada o norte de uma transformação e ampliação do PBF, seja pela baixa atenção e pela priorização necessárias para que fosse efetivamente selecionada na agenda decisória, seja pela ausência de apoio ou de contexto político favorável. De acordo com Jaccoud, as reformas da proteção social brasileira levaram a um "amplo debate em torno da pobreza e sua superação e um progressivo consenso em torno da necessidade de introdução de um programa nacional de transferência de renda" (Jaccoud, 2010).

É importante notar que o desenho escolhido para a aplicação do programa de transferência de renda brasileiro, o Bolsa Família, demonstra a prevalência de importantes imagens de problemas e de alternativas viáveis na produção de políticas que visam à ampliação da proteção social e à superação da pobreza e da vulnerabilidade. Tais conceitos devem ser articulados de forma conjunta, correlacionadas ao mundo do trabalho, dos direitos humanos e da intersetorialidade, que aproxima e entrelaça diferentes políticas sociais postuladas como universais, como saúde e educação, e a assistência aos pobres por meio da transferência de renda.

Jaccoud, Bichir e Mesquita (2017), por exemplo, mostram que os desenhos escolhidos permitiram a ampliação das capacidades estatais ao avançar nas ações interfederativas e intersetoriais. Exemplos dessa relação podem ser demonstrados pelos resultados expressivos permitidos pelo processo de acompanhamento das condicionalidades do Bolsa Família, ponto em que a renda básica, do ponto de vista conceitual, se distancia por princípio. As autoras levam em conta que esses ganhos, porém, devem ser considerados sob uma reinterpretação do processo punitivo que leva ao processo de exclusão e desligamento dos programas de transferência de renda, nesse caso.

A tensão entre cobertura universal e residual, porém, é anterior às questões que envolvem a renda básica e a renda mínima vinculada a condicionalidades. Pochmann (2007) demonstra, inclusive, que essa tensão responde a condicionantes estruturais, econômicos e institucionais que requerem o avanço da representação política, a institucionalização da democracia de massas e a constituição de elementos da moderna sociedade assalariada.

Mesmo assim, a proposta da renda básica universal e incondicional como solução a problemas públicos se mantém, em certa medida, presente no contexto das comunidades de políticas públicas e não sai do debate acadêmico e político, mesmo sem ter encontrado um ambiente favorável para sua adoção como alternativa. Ainda em períodos recentes, com destaque para os períodos eleitorais de 2014 e 2018, são múltiplos os episódios que recuperaram a ideia de renda básica universal.

Os desdobramentos da política brasileira com a abreviação do governo de Dilma Rousseff, em 2016, pareciam ter levado para longe qualquer possibilidade de retomada da renda básica à agenda e como alternativa aos problemas públicos no Brasil. Com as mudanças de prioridades e o desmonte progressivo das políticas públicas promovidas desde a posse de Michel Temer, continuadas em $2019 \mathrm{e}$ 2020, com a agenda conservadora de Jair Bolsonaro, restava pouco espaço na agenda governamental para discussões acerca de programas de transferência de renda universal, processo comum às demais construções em torno da proteção social brasileira em virtude do que Eduardo Fagnani (2017) descreve como fim do ciclo da cidadania social no Brasil.

Essa desconstrução se dá de forma institucional, política e prática, tendo como marco o documento do Partido do Movimento Democrático Brasileiro intitulado "Uma ponte para o futuro", ainda que este afirme, em seu primeiro parágrafo, se tratar de um programa que pretendia devolver "ao Estado a capacidade de executar políticas sociais que combatam efetivamente a pobreza e criem oportunidades para todos" (Partido do Movimento Democrático Brasileiro [PMDB], 2015). Mais do que mudanças 
nas prioridades governamentais, que poderiam manter, mas não ampliar, políticas já existentes, é importante destacar a forte atuação pelo desmonte das diversas políticas setoriais por meio da desarticulação de estruturas políticas e administrativas, descontinuidade de repasses financeiros e, de forma mais subjetiva, porém igualmente importante, pelas inúmeras tentativas de ressignificação dos sentidos e das imagens das políticas sociais, de educação, de saúde e da própria atuação e papel do Estado na promoção do bem-estar social com a aplicação, cada vez mais acentuada, de uma agenda ultraliberal.

Em 26 de março de 2020, todavia, o Plenário da Câmara dos Deputados aprovou a Lei no 13.982, que versa sobre o pagamento de um auxílio emergencial por 3 meses para todos os trabalhadores informais, retomando de forma inesperada preceitos basilares da renda básica. ${ }^{2} \mathrm{~A}$ iniciativa não pode ser encarada como uma ação do campo da política comum, em que grupos de pressão ou comunidades de políticas, em forte coalizão, conseguiram levar e aprovar o assunto ao plenário da Câmara. Também não deve ser encarado como uma proposta político-partidária do governo Bolsonaro, ou mesmo fruto da ação de um empreendedor de políticas.

A proposta de criação e implementação de uma renda básica emergencial emerge como resposta a um problema específico, em condições completamente atípicas e urgentes, cujo poder de atenção e de visibilidade rompe qualquer tipo de normalidade na tramitação de temas pela agenda governamental. Também há de considerar o caminho institucional percorrido para que a proposta fosse aprovada - sua origem se dá na movimentação dos atores envolvidos nos subsistemas e deságua no Poder Legislativo, desviando - e, em momentos finais, confrontando - o Poder Executivo, caracterizado neste momento de crise pela baixa capacidade propositiva e de coordenação de ações de enfrentamento aos problemas da pandemia.

É baseado nesse momento histórico, na análise de contexto, de mudança na agenda e na formulação de políticas públicas que este artigo pretende investigar e se aprofundar nas seguintes perguntas: quais são as características apresentadas pela pandemia da COVID-19 que fizeram com que temas e alternativas já conhecidos, como a renda básica, fossem resgatados e inseridos na agenda governamental como soluções viáveis em resposta às consequências avassaladoras da doença? Como entender o papel de um evento mundial catastrófico, que não se detém a barreiras geográficas ou à situação econômica, no processo de prioridades governamentais e escolha de alternativas para a produção de políticas públicas? É, portanto, com base na literatura de mudança e de formulação de políticas públicas, sobretudo no conceito de "eventos focalizadores" (focusig events), que este artigo pretende investigar tais questões.

\section{EVENTOS FOCALIZADORES E A PANDEMIA DA COVID-19}

A literatura de políticas públicas destaca a relevância de eventos repentinos e imprevisíveis, cujas consequências são dramáticas e largamente visíveis sobre o processo de produção de políticas públicas. Em especial, os estudos sobre formação da agenda, preocupados em explicar como problemas despertam a atenção da sociedade e dos governos, reservam consideração especial para elementos

\footnotetext{
${ }^{2}$ Prorrogações no pagamento do benefício e os valores pagos estão, atualmente, em discussão e negociação entre os atores políticos dos poderes Executivo e Legislativo. Recuperado de https:/g1.globo.com/economia/blog/ana-flor/post/2020/06/30/governo-vai-aceitarpagar-mais-duas-parcelas-de-r-600-do-auxilio-emergencial.ghtml
} 
dessa natureza. ${ }^{3}$ Anthony Downs identificou esses eventos como um dos elementos centrais do ciclo de atenção (issue-attention cycle). Para o autor, uma "série dramática de eventos" possibilita que problemas anteriormente excluídos da atenção do público sejam rapidamente convertidos em problemas sobre os quais o público se torna "consciente e alarmado" (1972).

Roger Cobb e Charles Elder (1971) também se referiram a eventos não antecipados como um dos elementos que poderiam promover a "iniciação de problemas" (issue initiation), ou seja, o processo de trazer ao centro da atenção pública uma questão que demanda resposta governamental. Os autores exemplificam mostrando que a questão racial nos Estados Unidos, inicialmente localizada e restrita ao plano individual, se transformara numa crise nacional e coletiva por meio de eventos trágicos (Cobb \& Elder, 1971). Para os autores, o processo de construção da agenda poderia resultar de mudanças que ocorrem nessas situações de ampla mobilização ou crise inesperada.

É John Kingdon (2003), entretanto, quem discutiu mais amplamente a relação entre eventos inesperados, a atenção e as mudanças em políticas públicas. $\mathrm{O}$ autor mostra que a atenção é um recurso escasso no processo de formulação de políticas públicas e que os tomadores de decisão se concentram em apenas algumas questões, desprezando outras. As questões que chamam a atenção dos policymakers são aquelas compreendidas como problemas e que demandam uma ação por parte do governo.

Há alguns mecanismos por meio dos quais os problemas passam a concentrar atenção dos formuladores, e um deles são os chamados eventos focalizadores (focusing events). ${ }^{4} \mathrm{Um}$ dos eventos focalizadores mais visíveis são desastres e crises de alta magnitude, que têm capacidade de mobilizar a atenção da sociedade e do governo de forma rápida e muito precisa. A relevância dos eventos focalizadores, para Kingdon, está em seu potencial para auxiliar na percepção e na definição de problemas. Aqui é útil lembrar o esquema geral em que o conceito de eventos focalizadores está inserido no modelo de múltiplos fluxos: mudanças na agenda governamental são o produto da convergência de três elementos (ou fluxos), isto é, problemas, soluções e contexto político. Dito de forma simplificada, problemas são ideias sobre as questões mais relevantes para uma sociedade, soluções são ideias sobre como lidar com as questões e contexto político envolve o ciclo eleitoral, a opinião pública e outros fatores circunstanciais. ${ }^{5}$

A mudança da agenda é o resultado da convergência destes 3 elementos - problemas, soluções e contexto político -, em breves momentos em que se configura uma oportunidade de mudança. Kingdon destacou o papel dos eventos focalizadores ao analisar o fluxo de problemas, considerando que um

\footnotetext{
${ }^{3}$ A análise sobre a COVID-19 como evento focalizador, que propomos aqui, é apenas uma entre as inúmeras possibilidades de reflexão, considerando o ferramental teórico e analítico da análise de políticas públicas. Com relação à agenda, estudos futuros podem explorar as distintas definições de problema adotadas pelo governo ao longo do tempo. Em relação às alternativas, podem-se explorar outras soluções para além da renda básica. Em termos do processo decisório, podem-se mapear os diversos atores envolvidos na tomada de decisão, suas escolhas e posicionamentos no curso da pandemia. Pensando no momento da implementação, há uma infinidade de ações a serem identificadas e investigadas, como o uso de tecnologias sociais, público-alvo, atuação das burocracias, relações federativas entre união, estados e municípios, sem mencionar os estudos avaliativos que poderão olhar em retrospectiva para o momento presente e contribuir para o aprendizado em políticas públicas.

${ }^{4}$ Os outros mecanismos incluem a divulgação de indicadores produzidos por pesquisas desenvolvidas pelo próprio governo ou por outros pesquisadores e que revelam a magnitude de um problema - um número crescente de acidentes nas estadas, por exemplo. $\mathrm{O}$ autor também aponta o feedback de ações governamentais decorrentes das práticas de monitoramento rotineiro e a avaliação da burocracia, que podem indicar falhas no desempenho de determinadas ações, fracasso no atingimento de resultados esperados ou produção de consequências não antecipadas. Para um debate mais aprofundado dos mecanismos de definição, ver Kingdon (2005), especialmente o Capítulo 5.

${ }^{5}$ Para uma análise mais detalhada do Modelo de Múltiplos Fluxos, consultar Capella (2007).
} 
evento de grande magnitude tem potencial para chamar a atenção para problemas que provavelmente já existiam, mas que não eram considerados prioritários.

Podemos, contudo, pensar que esses eventos podem ter um impacto relevante também no fluxo político. Um dos componentes do fluxo político é o "humor nacional", ou seja, as percepções mais gerais compartilhadas pela sociedade durante determinado período (Kingdon, 2003). Tais percepções, que envolvem a opinião pública ou movimentos sociais mais amplos, são sensíveis à cobertura midiática, ${ }^{6}$ que pode amplificar o alcance dos eventos focalizadores no debate social mais geral. Esse processo pode canalizar a atenção dos mais diferentes atores sociais, possibilitando o chamado "solo fértil" para algumas ideias. Esse parece ser o efeito que Baumgartner e Jones (1993) denominaram de "eventos desencadeantes" (triggering events). Para eles, esses eventos são importantes porque elevam uma questão que provavelmente já estava inserida na agenda, em geral, quando ocorre uma mudança na extensão ou no enquadramento da cobertura midiática, funcionando como "símbolos dramáticos de problemas" que consolidam percepções e entendimentos sobre problemas e que passam a concentrar fortemente a atenção (Baumgartner \& Jones, 1993).

Thomas Birkland (1997) amplia e desenvolve o conceito de evento focalizador proposto por Kingdon, formulando uma teoria específica sobre o impacto de crises e desastres acerca do processo de definição da agenda. Birkland $(1997,1998)$ investigou 4 casos, todos nos Estados Unidos, procurando compreender como eventos focalizadores influenciam o processo de produção de políticas públicas: o terremoto de São Fernando, ocorrido em 1971, no sul da Califórnia; o furacão Camille, de categoria 5, que afetou os estados de Alabama, Mississippi, Louisiana, além de alguns do Sul, em 1969; o desastre ecológico causado pelo vazamento do navio petroleiro Exxon Valdez, no Alasca, em 1989; e o acidente de Three Mile Island, o mais significativo acidente nuclear dos Estados Unidos, ocorrido em 1972, na Pensilvânia.

O autor concluiu que cada um deles é um evento único, apesar de compartilharem características que os definem como focalizadores. Ele parte do pressuposto de que há eventos potencialmente focalizadores, ou seja, que podem ganhar atenção do público e dos policymakers. Tais eventos reúnem 4 características: ocorrem de forma repentina e imprevista; são raros, imprevisíveis e não planejados; afetam um grande número de pessoas; o público e os membros mais informados em torno da política têm acesso à informação sobre a ocorrência do evento praticamente ao mesmo tempo.

Assim, um potencial evento focalizador é definido pelo autor como "repentino, relativamente raro, que pode ser razoavelmente definido como prejudicial ou que revela a possibilidade de danos futuros potencialmente maiores, de infligir danos ou sugerir danos potenciais que são ou podem ser concentrados em uma área geográfica ou comunidade de interesse definível e que são conhecidos pelos formuladores de políticas e o público simultaneamente" (Birkland, 1997).

A pandemia da COVID-19, causada pelo novo coronavírus, se espalhou pelo mundo de forma acelerada, causando milhares de mortes e colapsando sistemas de saúde em diversos países ao redor do mundo. A complexidade dessa pandemia extrapola qualquer limitação setorial que se tente fazer ao relacionar o problema como sendo de saúde pública, exclusivamente. As consequências econômicas,

\footnotetext{
${ }^{6}$ Os estudos de agenda desenvolvidos no campo da comunicação privilegiam a investigação das relações entre a agenda pública - o conjunto de questões que emergem e circulam na sociedade, envolvendo essas percepções mais gerais - e a agenda midiática - o conjunto de questões priorizadas pelos meios de comunicação. Sobre essa relação entre as agendas pública, midiática e de políticas públicas, consultar Dearing e Rogers (1996).
} 
sociais, no campo de emprego e renda, de assistência social e bem-estar social estão, nesse caso, diretamente relacionadas aos impactos e às consequências da doença.

Utilizando os critérios de Birkland (1997), podemos afirmar que a pandemia causada pelo novo coronavírus é um evento focalizador, pois satisfaz às 4 características definidas pelo autor rapidamente indicadas acima. Em primeiro lugar, a COVID-19 ocorreu de forma repentina e imprevista. Nas últimas décadas, a comunidade científica internacional tem demonstrado grande preocupação com a possibilidade de ocorrência de epidemias, principalmente em função da alta intensidade na movimentação de pessoas e mercadorias pelo planeta - como dengue, cólera, febre amarela, por exemplo, e também de novas doenças, como a Síndrome Respiratória Aguda Grave (Sars), febre hemorrágica causada pelo vírus ebola, influenza aviária, entre ouras (Carmo, Penna \& Oliveira, 2008). Portanto, a possibilidade de uma pandemia não configura, por si só, um evento focalizador. Porém, uma pandemia em decorrência do surto de Sars-Cov-2 na região de Wuhan, na China, em dezembro de 2019, é um evento repentino e imprevisto, em função das características epidemiológicas e clínicas do novo coronavírus, da alta transmissibilidade e da rapidez na progressão do contágio em escala global.

Ao caracterizar a pandemia da COVID-19 como evento focalizador no Brasil, consideramos as escolhas do governo federal, que estiveram longe de priorizar um conjunto de ações coordenadas para o enfrentamento da crise sanitária. O enfrentamento à pandemia demandou de todos os países ações coordenadas do poder central - não só do ponto de vista de saúde pública, mas também em relação a economia, trabalho, assistência social, segurança, entre outras. Embora o Sistema Único de Saúde (SUS) brasileiro conte com uma estrutura eficiente para chegar diretamente à população, o que seria fundamental para as estratégias de rastreamento de contatos e testagens, o governo federal foi orientado por uma representação de problema que variou entre negação (não há crise, não há motivo para pânico, é só uma gripe etc.), evitação (não há nada a ser feito), relativização (o maior problema não é o vírus, mas a economia) e a desresponsabilização (o problema é de estados e municípios).?

Essas escolhas sobre a representação do problema refletem uma busca contínua pela contenção da questão, numa tentativa de bloqueio da agenda governamental (Capella, 2016). Assim, apesar da magnitude do evento focalizador, e a despeito da previsibilidade de sua ocorrência e do conhecimento produzido por outros países, muitas das ações do governo federal brasileiro buscaram exatamente descaracterizar sua ocorrência como evento singular.

Por fim, pode-se afirmar que a COVID-19 no Brasil se enquadra sob a moldura conceitual de evento focalizador de Birkland, ao observarmos se tratar de um evento que se apresentou de forma arrebatadora, espalhando-se velozmente e atingindo um grande número de pessoas ao redor do país, gerando situações de emergência inesperadas, imprevisíveis, requerendo ações rápidas de controle, tratamento e prevenção não planejadas em nenhum dos diversos setores atingidos. Quer pela falta de posicionamento e coordenação das autoridades brasileiras, sobretudo da presidência da República, quer pelo tempo de resposta das burocracias e da necessidade de constatação do fato, em detrimento de suas possibilidades, as incertezas sobre a nova doença acabaram por gerar informações e alternativas que foram evoluindo no curso da pandemia.

\footnotetext{
${ }^{7}$ Muito sintomática dessa situação são as quatro mudanças no Ministério da Saúde: Luiz Henrique Mandetta foi substituído em 16 de abril de 2020 por Nelson Teich, que, por sua vez, deixou o Ministério da Saúde em 15 de maio de 2020, tendo sido conduzido para o cargo de ministro interino da saúde o general Eduardo Pazuello, posição na qual permaneceu por quatro meses. Pazuello foi, então, indicado oficialmente como Ministro da Saúde, o terceiro do governo de Jair Bolsonaro, em 14 de setembro de 2020. Em 15 de março de 2021, o presidente anunciou a substituição de Eduardo Pazuello pelo médico Marcelo Queiroga.
} 
Descobertas sobre desenvolvimento e evolução da doença, protocolos de tratamento, mecanismos de transmissão, formas de prevenção, adequação e posicionamento da sociedade brasileira frente às recomendações das autoridades, muitas vezes conflituosas e divergentes, são exemplos de informações que foram sendo sistematizadas e divulgadas para população, profissionais de saúde, tomadores de decisão e políticos simultaneamente, sobretudo informados pelas mesmas fontes: organizações internacionais como a OMS e a mídia.

A mídia, em especial, tem papel fundamental nos eventos focalizadores, como o da COVID-19, uma vez que a atenção do público nesse tipo de evento está bastante ligada à cobertura noticiosa, assim como se torna o principal canal de informação também dos policymakers. Quanto maior o escopo do evento - isto é, quanto maior o número de pessoas envolvidas; quanto mais amplos e tangíveis forem os efeitos, possíveis de serem mensurados ou convertidos em imagens; e quanto maior a raridade do acontecimento -, mais amplas tendem a ser as coberturas dos noticiários. Análises gráficas comparadas entre países, imagens impactantes como a do papa Francisco rezando sozinho na Praça São Pedro, no Vaticano, em 27 de março de 2020, ou a abertura de covas coletivas em diversas cidades do mundo e a realização de shows on-line (lives), são exemplos do poder de agenda da mídia em casos de eventos focalizadores como a COVID-19.

Ao contrário, entretanto, da agenda midiática, que reage imediatamente ao evento focalizador, a agenda governamental responde de forma mais lenta aos acontecimentos e depende, em grande parte, das características e das capacidades de resposta de cada área da política mais diretamente relacionada ao evento (policy domain). Em eventos focalizadores, a priorização e a ação governamental obedecem, portanto, a estímulos diferentes daqueles estabelecidas no processo de políticas públicas. Além disso, os eventos focalizadores conseguem fazer com que o tema ganhe prioridade absoluta na agenda governamental e com que o processo de seleção de alternativas seja reconfigurado. É com base nessa ideia que analisaremos, a seguir, a renda básica como opção viável no processo de seleção de alternativas que visaram ao combate às consequências da pandemia da COVID-19 no Brasil e no exterior.

\section{PRINCÍPIOS DA RENDA BÁSICA NA SELEÇÃO DE ALTERNATIVAS}

Para Birkland (1997), esses eventos não apenas concentram a atenção, como Kingdon havia mostrado, mas também têm grande potencial de favorecer alternativas no debate das comunidades de política. Como são eventos não planejados e imprevisíveis, repentinos e dramáticos, acabam por envolver toda a comunidade política, dentro e fora do governo, e favorecem a abertura de caminhos para a mudança. Esses momentos de crise criam oportunidades para a geração e a defesa de novas ideias, baseadas tanto em evidências - indicadores, dados estatísticos, informações oriundas de rotinas de monitoramento das ações, entre outros - quanto na interpretação desses elementos. 8 "Eventos focalizadores não ganham seu poder de foco a partir do acréscimo de evidências, mas sim de seu valor simbólico"9, diz Birkland (1997).

Isso significa que, aqueles que defendem determinada ideia do que fazer em relação ao problema (policy solution, nos termos de Kingdon), vão se apoiar em dados e evidências, mas também em

\footnotetext{
${ }^{8}$ Para uma discussão sobre a relevância da argumentação na produção de políticas públicas e sua relação com evidências e ideias, consultar Majone (1989).

9 Tradução nossa.
} 
símbolos, às vezes com alta carga emocional. As soluções que provavelmente contarão com aceitação e apoio entre os mais diferentes grupos sociais são aquelas que conseguem mobilizar o imaginário em torno do evento para garantir que a crise seja resolvida, ou que o grande problema não volte a ocorrer.

[...] um ator que tenha resultados de pesquisa plausíveis e um evento altamente visível, tangível e dramático a seu favor provavelmente se sairá melhor em um confronto político do que um outro ator apenas com dados de avaliação. Isso, por sua vez, pode levar a mudanças políticas não incrementais e mais rápidas à partir desse evento focalizador" (Birkland, 1997) ${ }^{10}$.

Assim, eventos focalizadores proporcionam oportunidades de defesa de ideias nas comunidades de políticas públicas.

Ainda de acordo com Bikland, 3 características parecem fundamentais para compreender as prioridades das ações governamentais na seleção de alternativas nesses momentos de crise: a natureza da comunidade de política relacionada ao evento - quanto mais organizada a comunidade, maior a influência de um evento focalizador para a mudança da agenda governamental -, o grau de participação pública na política - a reação de grupos organizados em torno de interesses relacionados ao evento é fundamental para que ele concentre a atenção dos policymakers e se mantenha na agenda governamental durante algum tempo - e a tangibilidade da crise - dados e indicadores mensuráveis para sustentar a caracterização da situação como grave e dependente da ação governamental.

No caso sob investigação, a pandemia da COVID-19 no Brasil, é preciso compreender de que forma a escolha e a formulação de uma política via auxílio emergencial, alternativa que resgata os preceitos da renda básica, é entendida como alternativa viável num contexto de crise gerada pelo evento focalizador. Considerando o histórico brevemente apresentado na Introdução deste artigo, a comunidade de política que se formou ao longo dos anos 1990 e 2000 acerca da renda mínima e das políticas de transferência de renda nunca saiu de cena, mesmo nos contextos menos favoráveis desde o pós-impeachment em 2016.

No que compete às escolhas de alternativas, é preciso pensar, num primeiro momento, na relevância que o histórico e a familiaridade com políticas de transferências de renda têm no processo de priorização e seleção de soluções possíveis. Não se podem descartar a experiência, o aprendizado da burocracia e os mecanismos presentes na estrutura institucional brasileira, assim como todo o legado do PBF, do Cadastro Único, do Suas e da atuação dos bancos públicos, como a Caixa Econômica Federal (CEF), como potenciais facilitadores dessa escolha por uma ação de transferência de renda que garanta condições mínimas de sobrevivência humana num período de crise. Não se trata de criar toda uma estrutura e um aparato novo, que demanda mais tempo do que uma crise pode oferecer, e sim de acionar, adaptar e ampliar capacidades e estruturas já existentes.

Ainda sobre a atuação e a organização das comunidades de políticas no processo de seleção de alternativas aos efeitos da pandemia no Brasil, é imprescindível lançar luz aos atores que, vendo uma possibilidade de abertura de uma janela de oportunidade em meio à crise, atuaram por meio de uma forte coalizão formada por Rede de Renda Brasileira Básica, Coalizão Negra por Direitos, Nossas, Instituto Ethos e Inesc, assim como pela própria mobilização social, fortemente informada

10 Tradução nossa. 
pela mídia, em prol da aprovação do benefício emergencial via transferência de renda direta (Ferreira, 2020; Orofino, 2020; Roque \& Ferreira, 2020).

O que se identifica por meio de reportagens jornalísticas do período e entrevistas concedidas por alguns desses atores envolvidos, entretanto, é que a proposta defendida por grupos organizados da sociedade civil, com evidentes esforços de coordenação, dirigiu seus esforços de incidência sobre o Poder Legislativo para alcançar o objetivo de aprovação de um desenho de política que atendesse a sua expectativa. O processo de escolha de lócus de atuação, também entendido pelo conceito de policy venue, é uma estratégia de atuação de atores e policymakers ao selecionarem o local mais favorável ou com maiores chances de reconhecimento e de adesão a suas propostas.

Segundo artigo de Orofino (2020), a manifestação dessas organizações no contexto da pandemia e na sua atuação na campanha por uma renda básica emergencial percebeu a intenção na adoção de implementar a transferência de renda diante da crise por parte do Poder Executivo federal com contornos e valores muito diferentes daqueles entendidos como mínimos e essenciais para superar o momento de pandemia. Ao retratar as propostas do Poder Executivo na adoção de políticas de transferência de renda, o coletivo Renda Básica Que Queremos (2020) diz:

[...] (o Poder Executivo) anunciou a intenção de fazer algo semelhante a isso, mas limitando-se a um número restrito de profissionais autônomos - cerca de 38 milhões de pessoas adultas, que receberiam R 200,00 por apenas 3 meses para sustentar toda a família [...] organizações da sociedade civil defendem uma proposta alternativa para alcançar o dobro de pessoas, pelo dobro de tempo, com menos burocracia e maior apoio para as famílias.

Ao resgatar sugestão inicial do governo brasileiro para o desenho e, especialmente, valores propostos, as organizações envolvidas no desenho da proposta revelaram que o ministro da Economia, Paulo Guedes, "ao dar a impressão de que o Executivo já estava fazendo o possível para lidar com a crise, se antecipava à sociedade civil e pautava o debate público a partir de sua própria avaliação do que 'pode' e do que 'não pode', elaborando uma proposta de governo abertamente insuficiente" (Orofino, 2020), tornando o Poder Executivo federal um terreno pouco fértil e pouco aberto à recepção de novas propostas e demandas de movimentos organizados. Compreende-se, assim, que o debate tenha se concentrado no Parlamento, onde o desenho da política aprovada encontrou um ambiente de discussão que permitisse a incorporação de elementos do debate público, incluindo a elevação dos valores incialmente propostos.

Os moldes e os desenhos escolhidos para a formulação dessa política de auxílio emergencial não partiram de um consenso, como é de esperar. Nas casas legislativas, Câmara e Senado, diversas propostas caminhavam em paralelo, dividindo opiniões e formando coalizões em torno de ideias e desenhos, incluindo e excluindo beneficiários, aumentando e diminuindo os valores do benefício da transferência, conforme destacado por Orofino (2002):

No Congresso, líderes da oposição propuseram um projeto que previa uma renda básica ambiciosa [...] No Senado, tramitava outro projeto, de autoria do senador Randolfe Rodrigues (Rede-AP). [...] o projeto em torno do qual se formava um consenso era o de autoria do deputado federal Eduardo Barbosa (PSDB-MG). 
A formulação da política de renda emergencial, da forma como foi aprovada, poderia ser totalmente diferente sem a interferência e a pressão das comunidades de políticas envolvidas no tema, sem o papel da mídia como principal veículo de informação em tempo real, sem a expertise de atores e instituições já existentes sobre tais mecanismos e, é claro, sem o exemplo de enfrentamento aos mesmos problemas públicos no ambiente internacional e recomendações de organismos internacionais (Leite, Peres \& Bellix, 2012) que já vinham implementando ações de complementação de renda, como a Alemanha e a China (Gentilini et al., 2020), locais onde a pandemia teve início e pico antes ao ocorrido no Brasil.

O tempo é uma variável de primeira ordem em situações emergenciais de desastres e crises, como esta que vivemos com a pandemia da COVID-19. Quanto maior e mais estruturada a comunidade de política, quanto menor o gap de informação entre público e tomadores de decisão, quanto maior o envolvimento público no processo e quanto maior a expertise sobre as soluções viáveis, maior a chance de seleção de uma alternativa e a formulação de política. Essas são as características primordiais para entender a forma como o auxílio emergencial via transferência de renda não apenas ascende à agenda, mas se torna uma solução imediatamente viável.

A tramitação acelerada na Câmara e no Senado, a pressão social pela aprovação da presidência da República sem vetos, sem maiores entraves e debates, somente foi possível pelas características do contexto político e social provocados pela pandemia. Em contexto normal, não marcado por um evento como a pandemia, tal incompatibilidade entre Legislativo e Executivo seria um cenário para disputas e negociações sem prazo para acabar. Eventos focalizadores aceleram esse processo e não oferecem tempo de negociação.

\section{CONSIDERAÇÕES FINAIS}

No Brasil, os estudos sobre eventos focalizadores são escassos, quase inexistentes. Isso se deve ao fato de que, na maioria dos casos, tais eventos são explorados, na literatura internacional, para analisar mudanças em políticas públicas motivadas pela ocorrência de desastres naturais, como furações, terremotos e tsunamis.

Nesta análise, procuramos identificar as características da pandemia da COVID-19 como evento focalizador à luz dos preceitos de Kingdon, Baumgartner e Jones e Birkland, ressaltando o potencial de agendamento e de seleção de alternativas na formulação de políticas públicas. Espera-se que outros estudos sejam desenvolvidos, ainda no campo da análise de políticas públicas, focalizando outros momentos do processo - estudos de formulação, implementação e avaliação, por exemplo -, utilizando outros referenciais teóricos promissores da área e que nos ajudam a compreender os múltiplos aspectos de uma questão complexa como a pandemia.

Entre as diversas ações governamentais propostas pelos tomadores de decisão, tomamos a renda emergencial via transferência de renda direta como objeto de análise, do agendamento à sua formulação. Ainda que de forma breve, pudemos entender, com forte embasamento teórico, as características da pandemia como um evento focalizador, sua ocorrência de forma imprevista e repentina, a raridade de ocorrência e a necessidade de lidar com inúmeros assuntos não planejados, o envolvimento direto entre público e policymakers e a influência na mídia no processo de informação sobre a ocorrência e as consequências do evento, além do grande número de pessoas e de áreas envolvidas.

Também pudemos analisar as características pertencentes aos pilares do renda básica como alternativa possível no processo de escolha e seleção na formulação de políticas: a existência de uma 
RAP | Eventos focalizadores e a pandemia da COVID-19: a renda básica emergencial na agenda governamental brasileira

comunidade de políticas públicas coesa, atuante e organizada; a participação e a mobilização social, com grande participação da mídia no processo de expansão do conflito e de concentração de atenção e proposição de soluções viáveis para amenizar os impactos econômicos nas famílias prejudicadas pela pandemia; a existência prévia de dados, indicadores, expertise e estruturas (burocracia, instituições, ferramentas); a atuação e o exemplo em órgãos internacionais e ações já implementadas para combater o mesmo cenário no exterior.

Longe de ser um estudo que se encerra aqui, esta breve análise busca entender o ponto de partida, as condições e os facilitadores de um evento focalizador no agendamento e na formulação de políticas. Grande destaque deverá ser dado, em estudos futuros, aos mecanismos de implementação; às capacidades estatais decorrentes da aprovação desse auxílio; seus limites, escopo, fragilidades e potencialidades.

Análises, como as propostas por Bartholo, Paiva e Souza (2020), Cardoso (2020), Chimini e Xavier (2020), Gonzales e Lotta (2020), já apontam para configuração do arranjo institucional do auxílio emergencial no governo federal, o mapeamento do público-alvo, os atores inseridos e excluídos no desenho, os problemas com tecnologias sociais, o uso de sistemas previamente existentes, a atuação da burocracia e as complexas relações federativas existentes no processo de desenho e implementação da política emergencial.

Novos estudos também devem se debruçar sobre as possibilidades de prorrogação e até de permanência desse auxílio emergencial visando à concretização da renda básica nos moldes originais: universal e não condicionado. Este estudo ilumina um de muitos caminhos possíveis de uma agenda que se abre em meio a um período tão complexo nas sociedades ao redor do mundo. 


\section{REFERÊNCIAS}

Bacha, E. L., \& Unger, R. M. (1978). Participação, salário e voto: um projeto de democracia para o Brasil. Rio de Janeiro, RJ: Paz e Terra.

Bartholo, L. Paiva, L. H. \& Souza, P. F. (2020, abril 03). O desafio de implantar o auxílio emergencial para os informais. Valor Econômico. Recuperado de https://valor.globo.com/opiniao/coluna/odesafio-de-implantar-o-auxilio-emergencial-paraos-informais.ghtml

Baumgartner, F., \& Jones, B. (1993). Agendas and instability in American politics. Chicago, IL: University of Chicago Press.

Bichir, R. M. (2010). O Bolsa Família na Berlinda? Novos Estudos CEBRAP, 87, 114-129.

Bichir, R. M. (2016). Novas agendas, novos desafios: reflexões sobre as relações entre transferência de renda e assistência social no Brasil. Novos Estudos CEBRAP, 35(1), 111-136.

Birkland, T. (1997). After Disaster: agenda-setting, public policy and focusing events. Washington, DC: Georgetown University Press.

Birkland, T. (1998). Focusing Events, Mobilization, and Agenda Setting. Journal of Public Policy, 18, 53-74.

Brasil, F. G. (2020). Estudos em Políticas Públicas e a COVID-19: Indicativos de uma agenda de pesquisa. Interseções, 22(3), 336-347.

Brasil, F. G., \& Capella, A. C. N. (2020). Janelas escancaradas: o potencial da Pandemia na mudança em políticas públicas. Boletim: Cientistas sociais e o coronavírus. Recuperado de http://www.anpocs. com/index.php/ciencias-sociais/destaques/2325boletim-semanal

Capella, A. C. N. (2007). Perspectivas Teóricas sobre o Processo de Formulação de Políticas Públicas. In G. Hochman, M. Arretche, \& E. Marques (Orgs.), Políticas Públicas no Brasil. Rio de Janeiro, RJ: Fiocruz.

Capella, A. C. N. (2016). Agenda-setting policy: strategies and agenda denial mechanisms". Organizações \& Sociedade, 23(79), 675-691.

Capella, A. C. N., \& Brasil, F. G. (2016). Análise de políticas públicas: uma revisão da literatura sobre o papel dos subsistemas, comunidades e redes. Novos estudos CEBRAP, 101, 57-76.
Cardoso, B. B. (2020). A implementação do Auxílio Emergencial como medida excepcional de proteção social. Revista de Administração Pública, 54(4), 1052-1063.

Carmo, E. H., Penna, G., \& Oliveira, W. K. (2008). Emergências de saúde pública: conceito, caracterização, preparação e resposta. Estudos Avançados, 22(64), 19-32.

Chimini, L., \& Xavier, S. (2020, maio 18). Auxílio Emergencial e a burocracia que tritura gente. Outras Palavras. Recuperado de https://outraspalavras.net/ crise-brasileira/auxilio-emergencial-e-a-burocraciaque-tritura-gente/

Cobb, R., \& Elder, C. (1971). The Politics of AgendaBuilding: An Alternative Perspective for Modern Democratic Theory. Journal of Politics, 33(4), 892-915.

Coêlho, D. B. (2013). A agenda social nos governos FHC e Lula: competição política e difusão do modelo renda mínima. In G. Hochman, \& C. A. P. Faria (Orgs.), Federalismo e políticas públicas no Brasil. Rio de Janeiro, RJ: Fiocruz.

Dearing, J., \& Rogers, E. (1996). Agenda-setting. Thousand Oaks, CA: Sage.

Downs, A. (1972, Summer). Up and Down with Ecology - The Issue Attention Cycle. Public Interest, 28, 38-50.

Fagnani, E. (2017, junho). O fim do breve ciclo da cidadania social no Brasil (1988-2015) (texto para discussão, no 308). Campinas, SP: IE/UNICAMP.

Farah, M. F. S. (2008). Disseminação de inovações e políticas públicas e espaço local. Organizações \& Sociedade, 15(45), 121-126.

Ferreira, L. T. (2019). Renda básica - controvérsia e implementação (Dissertação de Mestrado). Universidade Federal do ABC, São Bernardo do Campo, SP.

Ferreira, L. T. (2020, abril 29). Uma via expressa para a renda básica universal? Le Monde Diplomatique Brasil. Recuperado de https://diplomatique.org.br/ uma-via-expressa-para-a-renda-basica-universal/

Gentilini, U., Almenfi, M. B. A., Dale, P., Demarco, G. C., \& Santos, I. V. (2020, May 1). Social Protection and Jobs Responses to COVID-19: A Real-Time Review of Country Measures. COVID-19 Living Paper. Washington, DC: World Bank Group. Recuperado 
de http://documents.worldbank.org/curated/ en/883501588611600156/Social-Protection-andJobs-Responses-to-COVID-19-A-Real-TimeReview-of-Country-Measures-May-1-2020

Gonzales, L, \& Lotta, G. (2020, setembro 21). Erros de gestão podem deixar 6 milhões de famílias sem auxílio na pandemia. Folha de São Paulo. Recuperado de https://wwwl.folha.uol.com.br/mercado/2020/09/ erros-de-gestao-podem-deixar-6-milhoes-defamilias-sem-auxilio-na-pandemia.shtml

Leite, C. K. S., Peres, U. D. (2015). Paradigmas de Desenvolvimento e Disseminação de Políticas: Raízes Locais da Criação do Programa Bolsa Família. Organizações \& Sociedade, 22(75), 621-638.

Leite, C. K. S., Peres, U. D., \& Bellix, L. (2012). Disseminação e inovação de políticas sociais na América Latina: Uma análise dos programas de transferência de renda condicionada no Brasil e no México. In Anais do $36^{\circ}$ Encontro Anual da ANPOCS, Águas de Lindóia, SP.

Jaccoud, L. (2010). O Programa Bolsa família e o combate à pobreza: Reconfigurando aproteção social no Brasil? In J. A. Castro, \& L. Modesto (Orgs.), Bolsa Família 2003-2010: Avanços e desafios (Vol. 1, pp. 101-135). Brasília, DF: Ipea.

Jaccoud, L., Bichir, R., \& Mesquita, A. C. (2017). OSUAS na proteção social brasileira: Transformações recentes e perspectivas. Novos estudos CEBRAP, 36(2), 37-53. Recuperado de https://doi. org/10.25091/s0101-3300201700020003

Majone, G. (1989). Evidence, Argument \& Persuasion in the Policy Process. New Haven, CO: Yale University Press.

March, J. G. (2009). Como as Decisões Realmente Acontecem: princípios da tomada de decisões. São Paulo, SP: Leopardo.

March, J. G., Olsen, Johan P., \& Cohen, M. D. (1972). A Garbage Can Model of Organizational Choice. Administrative Science Quartely, 17, 1-25.

Orofino, A. (2020, maio). O Levante: Como nasceu a inédita mobilização que, em questão de dias, forçou o governo a pagar uma renda básica aos mais pobres. Revista Piauí. Recuperado de https://piaui.folha.uol. com.br/materia/o-levante/

Partido do Movimento Democrático Brasileiro. (2015). Uma ponte para o futuro. Brasília, DF:
Fundação Ulysses Guimarães. Recuperado de https://www.fundacaoulysses.org.br/wp-content/ uploads/2016/11/UMA-PONTE-PARA-OFUTURO.pdf

Pochmann, M. (2007, outubro). Segurança social no capitalismo periférico: algumas considerações sobre o caso brasileiro. Nueva Sociedad. Recuperado de https://nuso.org/articulo/seguranca-social-nocapitalismo-periferico-algumas-consideracoessobre-o-caso-brasileiro/

Renda Básica Que Queremos. (2020, março 23). Nota técnica da campanha Renda Básica que Queremos: Proposta de Renda Básica Emergencial voltada aos mais desprotegidos durante a pandemia do Coronavírus. Recuperado de http://rendabasica. com.br/rbrb-biblioteca/nota-tecnica-renda-basicaemergencial-contra-os-impactos-do-coronavirus/

Roque, T., \& Ferreira, L. (2020, março 30). Renda básica, antes folclórica, vira medida essencial para enfrentar crise do coronavírus. Folha de S. Paulo. Recuperado de https://www1.folha.uol.com.br/ ilustrissima/2020/03/renda-basica-antes-folcloricavira-medida-essencial-para-enfrentar-crise-docoronavirus.shtml

Silva, J. P. (2014). Por que Renda Básica? São Paulo, SP: Annablume.

Silva, M. O., Yazbek, M. C., \& Di Giovanni, G. A. (2012). Política social brasileira no século XXI: a prevalência dos programas de transferência de renda (6a ed.). São Paulo, SP: Cortez Editora.

Silveira, A. M. (1975). Redistribuição da renda. Revista Brasileira de Economia, 29(2), 3-15.

Soares, F. V., Soares, S., Medeiros, M., \& Osório, R. G. (2006, outubro). Programas de Transferência de Renda no Brasil: Impactos sobre a desigualdade (Texto para discussão, No 1228). Brasília, DF: Instituto de Pesquisa Econômica Aplicada. Recuperado de http:// www.ipea.gov.br/portal/images/stories/PDFs/TDs/ td_1228.pdf

Sposati, A. (1997). Sobre os programas brasileiros de garantia de renda mínima - PGRM. In A. Sposati (Org.), Renda mínima e crise mundial, saída ou agravamento? São Paulo, SP: Cortez.

Suplicy, E. M. (2013). Renda de Cidadania - A saída é pela porta. São Paulo, SP: Cortez Editora. 


\section{Felipe Gonçalves Brasil}

https://orcid.org/0000-0001-7282-0110

Doutor em Ciência Política; Jovem Pesquisador FAPESP; Docente na graduação e no Mestrado em Gestão de Políticas Públicas da Escola de Artes, Ciências e Humanidades da Universidade de São Paulo (EACH-USP). E-mail: fbrasil.pp@gmail.com

\section{Ana Cláudia Niedhardt Capella}

https://orcid.org/0000-0002-1423-898X

Doutora em Ciências Sociais; Docente no Departamento de Administração Pública da Universidade Estadual Paulista "Júlio de Mesquita Filho" (UNESP), campus Araraquara; Docente no Programa de Pós-Graduação em Ciência Política da Universidade Federal de São Carlos (UFSCar).E-mail: ana.capella@gmail.com

\section{Leandro Teodoro Ferreira}

Mestre em Políticas Públicas pela Universidade Federal do ABC (UFABC). E-mail: leandrogpp@gmail.com 